\title{
Investigation of Sida acuta (Wire Weed) Plant Extract as Corrosion Inhibitor for Aluminium-Copper-Magnessium Alloy in Acidic Medium
}

\author{
Fatai Afolabi Ayeni ${ }^{*}$, Saheed Alawode1, Dorcas Joseph ${ }^{1}$, Patrick Sukop1, \\ Victoria Olawuyi ${ }^{1}$, Temitope Emmanuel Alonge ${ }^{1}$, Oladuuni Oyelola Alabi ${ }^{1}$, \\ Oluwakayode Oluwabunmi ${ }^{2}$, Francis Ireti $\mathrm{Alo}^{3}$

\footnotetext{
${ }^{1}$ National Metallurgical Development Centre (NMDC), Jos, Nigeria

${ }^{2}$ Prototype Engineering Development Institute (PEDI), Ilesha, Nigeria

${ }^{3}$ Materials Science and Engineering, Obafemi Awolowo University, Ile Ife, Nigeria

Email: ${ }^{*}$ ayeflo@yahoo.com
}

Received 11 April 2014; revised 13 May 2014; accepted 21 May 2014

Copyright (C) 2014 by authors and Scientific Research Publishing Inc.

This work is licensed under the Creative Commons Attribution International License (CC BY). http://creativecommons.org/licenses/by/4.0/

\section{(c) (7) Open Access}

\begin{abstract}
This work is an investigation of the aqueous corrosion inhibition of Al-Cu-Mg Alloy in acidic medium using extract of Sida acuta (wire weed) plant as corrosion inhibitor at $10 \%, 20 \%, 30 \%$ and $40 \% \mathrm{v} / \mathrm{v}$ of the extract. After exposing the alloy to the medium, the results showed that the plant extract inhibited the acid induced corrosion. The presence of Sida acuta plant extract reduces corrosion rate from 0.0012 to $0.0001 \mathrm{MPY}$ and percentage protection increases from $37.42 \%$ to 93.63\% within a ten-day period with increase in percentage volume of the extract. The result has clearly shown that Sida acuta plant extract can be used as a corrosion inhibitor in the part of chemical plant that is made of Al-Cu-Mg Alloy where acid is used for descaling and cleaning.
\end{abstract}

\section{Keywords}

Corrosion Inhibition, Sida acuta, Immersion Corrosion Test, Weight Loss, Percentage Protection, Acid Induced Corrosion

\section{Introduction}

Pure metals and alloys react chemically/electrochemically with corrosive medium to form a stable compound in which the loss of metal occurs. The compound so formed due to this loss of metal is a corrosion product com-

${ }^{*}$ Corresponding author.

How to cite this paper: Ayeni, F.A., et al. (2014) Investigation of Sida acuta (Wire Weed) Plant Extract as Corrosion Inhibitor for Aluminium-Copper-Magnessium Alloy in Acidic Medium. Journal of Minerals and Materials Characterization and Engineering, 2, 286-291. http://dx.doi.org/10.4236/jmmce.2014.24033 
monly known as rust. Corrosion is defined as the destruction, degradation or deterioration of material due to reaction between the material and the environment [1].

Many factors need to be considered when selecting engineering materials, but for chemical process plant the overriding consideration is usually the ability to resist corrosion [1]. Some metals and alloys are known for their resistance to corrosion but in extreme conditions, they corrode.

The chemical process plants used in textile and food processing plant make use of $\mathrm{Al}-\mathrm{Cu}-\mathrm{Mg}$ alloy where the use of mild steel would cause contamination [2]. Acid and alkalis are used for cleaning and descaling of this part of the plant. In addition to these cleaning and descaling process, these chemicals corrode the alloy thereby reducing the performance and the life span of the engineering materials.

In order to combat this constant and continuous problem, which is often difficult to eliminate completely, the use of inhibitor is one of the best options deployed for protecting metals and alloys against corrosion over the years. Considerable efforts have been made to find suitable corrosion inhibitor in various corrosive media. The known hazardous effects of most synthetic process have urged researchers to look beyond inhibitors that could not offer sustainable environment, especially in view of $\mathrm{Cr}$ (VI) being banned and labelled as a carcinogen. Corrosion control of metals is of technical, environmental and aesthetical importance. This has prompted the search for green inhibitor.

The adsorption of the inhibitors unto the metal/alloy surfaces retards the cathodic or anodic electrochemical processes that accompany corrosion of the metal/alloy [3] [4]. Studies have shown that the efficiency of inhibition is related to the amount of adsorbed inhibitor on the metal surface [5]. The inhibitor after adsorption may form a surface film that acts as a physical barrier restricting the diffusion of ions/molecules to or from the metal/ alloy surface and may prevent the metal atoms from participating in either the anodic or cathodic reactions of corrosion [6] [7].

In the search for more environmentally friendly and readily available inhibitors, researchers have reported the use of local plants such as Vernonia amygdalina [8] and neem leaf [9]. The use of plant extracts as organic inhibitors for the corrosion of metals/alloys, has gained very wide interest among researchers in recent time [10] [11].

Green corrosion inhibitors are biodegradable and do not contain heavy metals or other toxic compounds. The use of naturally occurring plant extracts as inhibitors is particularly interesting and economical because they are cheap, non-toxic, ecologically friendly and poses little or no threat to the environment [3] [12]. Therefore, while reducing corrosion rate in metals, green inhibitors take care of environmental pollution constituted by earlier suggested inhibitors. In addition to being environmentally friendly and ecologically acceptable, plant products are inexpensive, readily available and renewable. Hence, green inhibitors show real promise. Sida acuta is a species of flowering plant in the family, Malvaceae and it is a weed that frequently dominates pastures [13]. The plant is native to Mexico and Central America but has spread throughout the tropics and subtropics [14]. Its use for curing of fever is the most cited. The administration may be by oral route for example in the case of fever or by external application of the paste directly on the skin for skin diseases or snake bites [15].

The aim of this research work is to investigate the effect of Sida acuta plant extracts as corrosion inhibitor for $\mathrm{Al}-\mathrm{Cu}-\mathrm{Mg}$ alloy in acidic medium.

\section{Materials and Method}

\subsection{Materials}

The materials used for the experiment include: Al-Cu-Mg alloy ( $\mathrm{Al}-95.5 \%, \mathrm{Cu}-4.0, \mathrm{Mg}-0.5 \%$ ) Sida acuta plant extract, concentrated $\mathrm{HCl}$, distilled water, detergents and alcohol.

\subsection{Equipment}

The equipment used in the research work included $250 \mathrm{~mL}$ beakers, $250 \mathrm{~mL}$ conical flask, $1000 \mathrm{~mL}, 500 \mathrm{~mL}$ beaker, measuring cylinder, hack saw, metal file, emery cloth, clamp, vernier calliper, digital weighing balance, laboratory oven, brush, retort stands, threads, water bath, hand gloves.

\subsection{Method}

\subsubsection{Extraction of Sida acuta Plant Extract}

The leaves and stem of Sida acuta were collected, rinsed with distilled water and allowed to dry. The plant was 
grinded and then weighed with weighing balance. $500 \mathrm{~mL}$ of distilled water was added to $150 \mathrm{~g}$ of the blended plant and mixed. The resulting mixture was sieved to obtain the extract.

\subsubsection{Experimental Procedure}

After casting, the aluminium alloy was cut and machined to corrosion coupons (cylindrical shape) of dimension $1.5 \times 1 \mathrm{~cm}$. The corrosion test was based on weight loss methods. Twenty five coupons were produced for different concentration of inhibitor $(10 \%, 20 \%, 30 \%$ and $40 \%)$ in the $0.5 \mathrm{M} \mathrm{HCl}$ solution and reference medium which was $0.5 \mathrm{M} \mathrm{HCl}$ solution without inhibitor. The coupons were polished and degreased in absolute ethanol, dried, weighed and stored in desiccators. The weight loss of each coupon was determined at 2 days interval for 10 days. Then the rate of corrosion, inhibition efficiency and degree of surface coverage were determined. The experiment was conducted at room temperature in the range of $26^{\circ} \mathrm{C}-30^{\circ} \mathrm{C}$.

\subsubsection{Determination of Corrosion Rate (MPY) and Percentage Protection (\%)}

The weight loss was determined by finding the difference between initial and final weight of coupon after 2 days (because there would have been a tangible weight loss within the period) of immersion from the relationship(s) [16].

$$
W=W_{o}-W_{f}
$$

where $W$-weight loss, $W_{o}$-initial weight, $W_{f}$-final weight.

The standard expression for measurement of corrosion rate in mils per year (MPY) was used which is given as follows [14] [17].

$$
\text { Corrosion rate }(\text { MPY })=\frac{534 W}{D A T}
$$

where MPY — mils per year, $W$-weight loss in g, $D$-density of the materials in g/cc, $T$-time of exposure in hours, $A$-area in in ${ }^{2}$.

The inhibition efficiency was determined using the relationship [3] [7]:

$$
\text { Inhibitor efficiency }=\frac{W_{o}-W}{W_{o}} \times 100 \%
$$

where $W$ and $W_{o}$ are the corrosion rates with and without inhibitor respectively.

Adsorption consideration.

The percentage protection at each concentration of inhibitor was evaluated using the equation [18].

$$
\text { Percentage protection }(\%)=\frac{W_{b}-W_{i}}{W_{b}} \times 100
$$

where $W_{b}$ and $W_{i}$ are the weight loss in corrodent without and with inhibitor respectively.

\section{Results and Discussion}

\subsection{Results}

To determine the effect of length of exposure on weight loss, corrosion rate, inhibitor efficiency and percentage protection, coupons were retrieved at different exposure times for analysis. Readings were taken at room temperature using different percentage volume of Sida acuta extract. Figure 1 shows the variation of the weight loss with time of exposure for the reference and four different inhibitor concentrations in the $0.5 \mathrm{M} \mathrm{HCl}$ solution. Figure 2 is the corrosion rates variation with time of exposure for different inhibitor concentrations in the hydrochloric acid solution. Figure 3 shows the variation of inhibitor efficiency with exposure time at various inhibitor concentration, while Figure 4 shows the percentage protection with inhibitor concentration for different time of exposure.

\subsection{Discussion}

Coupons were pulled from the medium at four-exposure time. All the acidic solutions with Sida acuta extract 


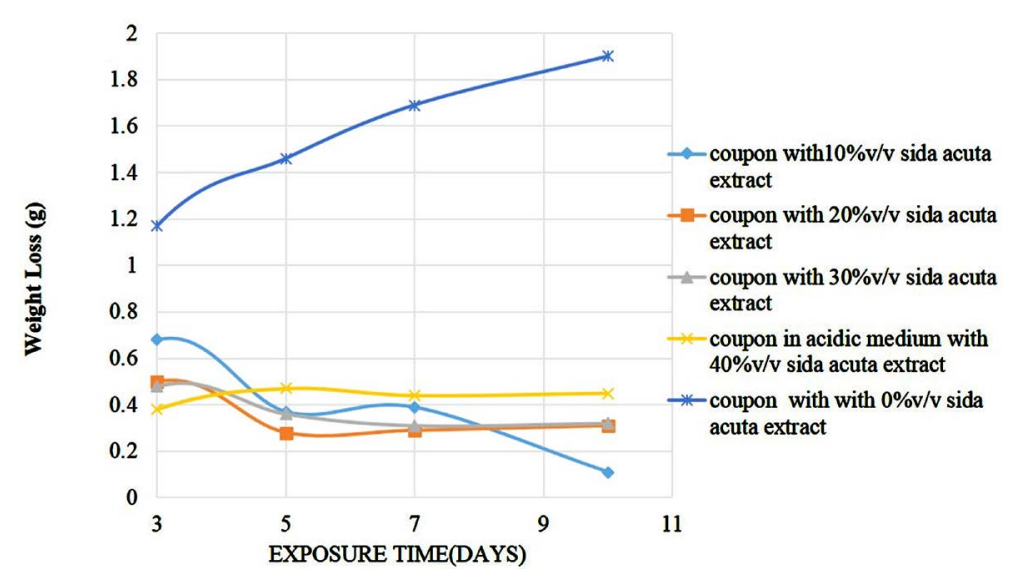

Figure 1. Weight loss of alloy in acidic medium against exposure time at different \% v/v Sida acuta extract.

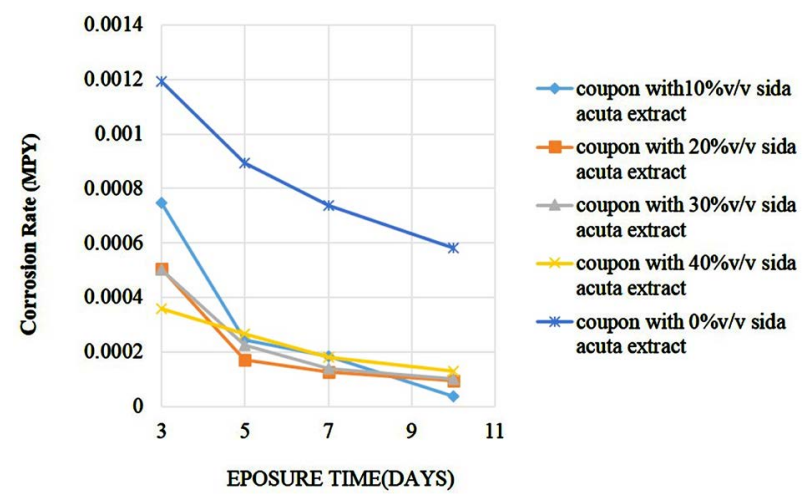

Figure 2. Corrosion rate of alloy in acidic medium against exposure time.

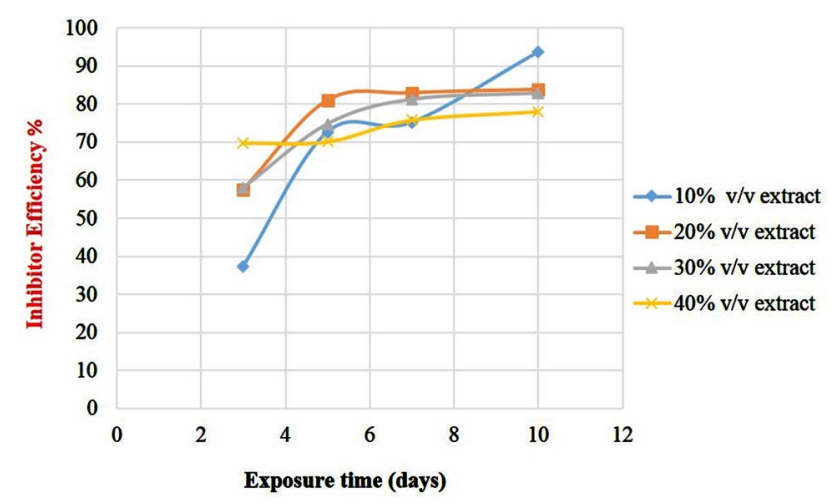

Figure 3. Variation of inhibitor efficiency with time.

were found to inhibit corrosion. After 3rd day the solution with $10 \%$ Sida acuta extract gave the highest weight loss of $0.68 \mathrm{~g}$ followed by the solution containing $20 \% \mathrm{v} / \mathrm{v}$ Sida acuta extract (weight loss of $0.5 \mathrm{~g}$ ) down to solution with $40 \%$ of the extract with weight loss of $0.38 \mathrm{~g}$. Under the same condition, the blank coupon (coupon in the medium without inhibitor) gave $1.17 \mathrm{~g}$ weight loss. Comparing the inhibited and blank coupon results at this exposure days; $0.49 \mathrm{~g}, 0.67 \mathrm{~g}, 0.69 \mathrm{~g}$, and $0.79 \mathrm{~g}$ of the coupon was saved from corrosion in the acidic solution containing; $10 \%, 20 \%, 30 \%$ and $40 \% \mathrm{v} / \mathrm{v}$ Sida acuta extract respectively. The weight loss increases with time of exposure. On the third day, solution with $40 \%$ extract gave the lowest weight loss but highest weight loss on the tenth day. In contrast, coupon in solution containing $10 \%$ extract gave the highest weight loss on the 


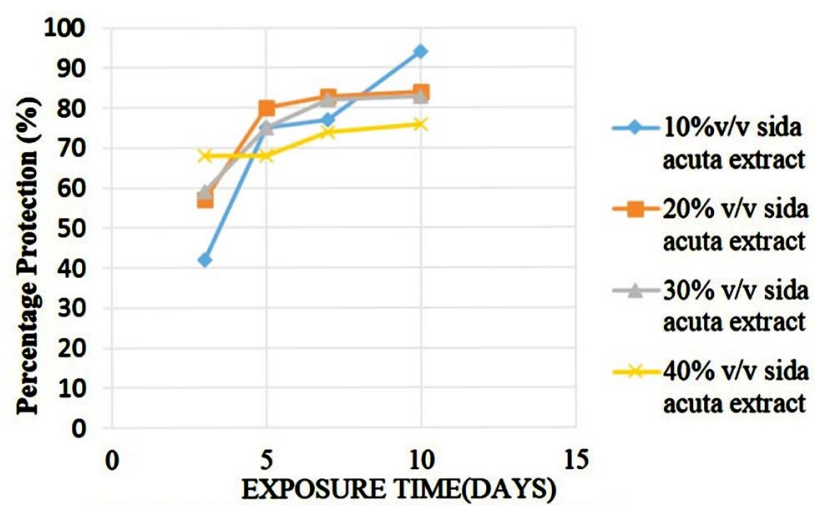

Figure 4. Effect of \% v/v Sida acuta extract on surface coverage in acidic medium.

third day but the least weight loss on the tenth day. This shows that to have better inhibition in acidic medium at long exposure time such as ten days, it is recommended that the percentage volume inhibitor should be $10 \%$, but at a shorter time of three days, $40 \% \mathrm{v} / \mathrm{v}$ of the extract is advisable to be used.

Figure 2 shows that corrosion rate decreases with exposure time in the presence of the extract. Comparing with the medium without inhibitor, there is a good indication that the rate of penetration of the corrodent is reduced. The significant decrease in corrosion rate of medium with inhibitor can be attributed to the adsorption of molecule of the inhibitor on the alloy surface, since this inhibitor molecule acts as physical barrier to restrict the diffusion of ions to and from the alloy and then prevent the alloy atoms (ions) from participating in further anodic or cathodic reactions, hence resulting in decrease in the corrosion rate [13]. The plant extract molecule can adsorb on the alloy surface and block the active sites on the surface, thereby reducing the corrosion rate in the medium.

From the plot of inhibition efficiency against exposure time (Figure 3), it can be seen that $10 \%$ inhibitor concentration has the highest protection efficiency and this increase with time of exposure, from $37.42 \%$ at third day to $75.2 \%$ at the seventh day and $93.63 \%$ at the tenth day. This shows that the inhibitor acts best within ten days at $10 \%$ inhibitor concentration.

The percentage protection is presented in Figure 4. In each of the solution, the highest percentage protection was on tenth day with $10 \% \mathrm{v} / \mathrm{v}$ of the extract, an indication for better protection at longer exposure time.

\section{Conclusions}

The results presented in this work show that Sida acuta extract inhibits corrosion of Al-Cu-Mg alloy in $\mathrm{HCl}$ medium at room temperature. The choice of $\mathrm{HCl}$ with the inhibitor for pickling of metals and cleaning scales will be one of the best choices when compared to other mineral acids since some other mineral acids like $\mathrm{HF}^{-\mathrm{HNO}_{3}}$ mixture results in the disadvantage of nitrous gas emission and nitrate effluent, which pollute the environment.

Therefore, in textile and food industries where processing plants make use of $\mathrm{Al}-\mathrm{Cu}-\mathrm{Mg}$ in the machine parts, the process of cleaning, pickling and descaling can be done using $\mathrm{HCl}$ with Sida acuta as the inhibitor. This will be more economical and efficient, and play a vital role in reducing corrosion rate.

\section{References}

[1] Abdallah, M. (2004) Guar Gum as Corrosion Inhibitor for Carbon Steel in Sulphuric Acid Solutions. Portugaliae Electrochimica Acta, 22, 161-175. http://dx.doi.org/10.4152/pea.200402161

[2] Abiola, O.K., Oforka, N.C., Ebenso, E.E. and Nwinuka, N.M. (2007) Eco-Friendly Corrosion Inhibitors: The Inhibitive Action of Delonix Regia Extract for the Corrosion of Aluminium in Acidic Media. Anti-Corrosion Methods and Materials, 54, 219-224. http://dx.doi.org/10.1108/00035590710762357

[3] Kuznetsov, Y.I. (2004) Physicochemical Aspects of Metal Corrosion Inhibition in Aqueous Solutions. Russian Chemical Reviews, 73, 75-87. http://dx.doi.org/10.1070/RC2004v073n01ABEH000864

[4] Ebenso, E.E. (2003) Corrosion Inhibition Studies of Some Plant Extracts on Aluminium in Acidic Medium. Materials Chemistry and Physics, 79, 58-62. http://dx.doi.org/10.1016/S0254-0584(02)00446-7 
[5] Adeyemi, O.O. (2006) Effect of Temperature and Concentration on Protective Action of 5 Membered Heterocycles on Acid Corrosion of Brass. Journal of Corrosion Science and Technology, 3, 40-45.

[6] Oguize, E.E., Okolue, B.N., Ogukwe, C.E. and Onuchukwu, A.I. (2004) Studies on the Inhibitive Action of Methylene Blue Dye on Aluminium Corrosion in KOH Solution. Journal of Corrosion Science and Technology, 1, 88-91.

[7] Chetouani, A., Hanmouti, B. and Benkaddour, M. (2004) Corrosion Inhibition of Iron in Hydrochloric Acid Solution byJojoba Oil. Pigment and Resin Technology, 33, 26-31. http://dx.doi.org/10.1108/03699420410512077

[8] Loto, C.A. and Muhammed, A.I. (2005) The Effect of Cashew Juice Extract on the Corrosion Inhibition of Mild Steel in HCl. Corrosion Prevention and Control, 47, 13-22.

[9] Okafor, P.C. (2007) Eco Friendly Corrosion Inhibitors: Inhibitive Action of Ethanol Extracts of Garcinia Kola for the Corrosion of Mild Steel in $\mathrm{H}_{2} \mathrm{SO}_{4}$ Solution. Pigment Resin Technology, 36, 5-8. http://dx.doi.org/10.1108/03699420710820414

[10] Davis, G.D., Fraunhofer, J.A., Krebs, L.A. and Dacres, C.M. (2001) The Use of Tobacco Extracts as Corrosion Inhibitor. CORROSION 2001 Paper No. 58, NACE, Houston.

[11] Loto, C.A. (1998) The Effect of Bitterleaf Extracts on Corrosion of Mild Steel in $0.5 \mathrm{M} \mathrm{HCl}$ and $\mathrm{H}_{2} \mathrm{SO}_{4}$ Solutions. Nigeria Corrosion Journal International, 1, 19-20.

[12] Bendahou, M.A., Benadellah, M.B.E. and Hammouti, B.B. (2006) A Study of Rosemary Oil as a Green Corrosion Inhibitor for Steel in $2 \mathrm{M} \mathrm{H}_{3} \mathrm{PO}_{4}$. Pigment and Resin Technology, 35, 95-100. http://dx.doi.org/10.1108/03699420610652386

[13] Bouklah, M., Hammouti, B., Benhadda, T. and Benkadour, M. (2005) Thiophene Derivatives as Effective Inhibitors for the Corrosion of Steel in $0.5 \mathrm{M} \mathrm{H}_{2} \mathrm{SO}_{4}$. Journal of Applied Electrochemistry, 35, 1095-1101. http://dx.doi.org/10.1007/s10800-005-9004-Z

[14] Blin, F., Leary, S.G., Wilson, K., Deacon, G.B., Junk, C. and Forsynth, M. (2004) Corrosion Mitigation of Mild Steel by New Rare Earth Cinnate Compounds. Journal of Applied Electrochemistry, 34, 591. http://dx.doi.org/10.1023/B:JACH.0000021932.87043.7b

[15] Bouyanzer, A. and Hammouti, B. (2004) A Study of Anti-Corrosive Effects of Artemisia Oil on Steel. Pigment and Resin Technology, 33, 287-292. http://dx.doi.org/10.1108/03699420410560489

[16] Loto, C.A., Loto, R.T. and Popoola, A.P.I. (2011) Effect of Neem Leaf (Azadirachita indica) Extract on the Corrosion Inhibition of Mild Steel in Dilute Acids. International Journal of the Physical Sciences, 6, 2249-2257.

[17] Loto, C.A. (2003) The Effect of Bitterleaf on the Inhibition of Mild Steel in $\mathrm{HCl}$ and $\mathrm{H}_{2} \mathrm{SO}_{4}$. Corrosion Prevention and Control Journal, 50, 43-49.

[18] Avwiri, G.O. and Igho, F.O. (2003) Inhibitive Action of Vernonia amygdalina on the Corrosion of Aluminium Alloys in Acidic Media. Materials Letters, 57, 3705-3711. http://dx.doi.org/10.1016/S0167-577X(03)00167-8 
Scientific Research Publishing (SCIRP) is one of the largest Open Access journal publishers. It is currently publishing more than 200 open access, online, peer-reviewed journals covering a wide range of academic disciplines. SCIRP serves the worldwide academic communities and contributes to the progress and application of science with its publication.

Other selected journals from SCIRP are listed as below. Submit your manuscript to us via either submit@scirp.org or Online Submission Portal.
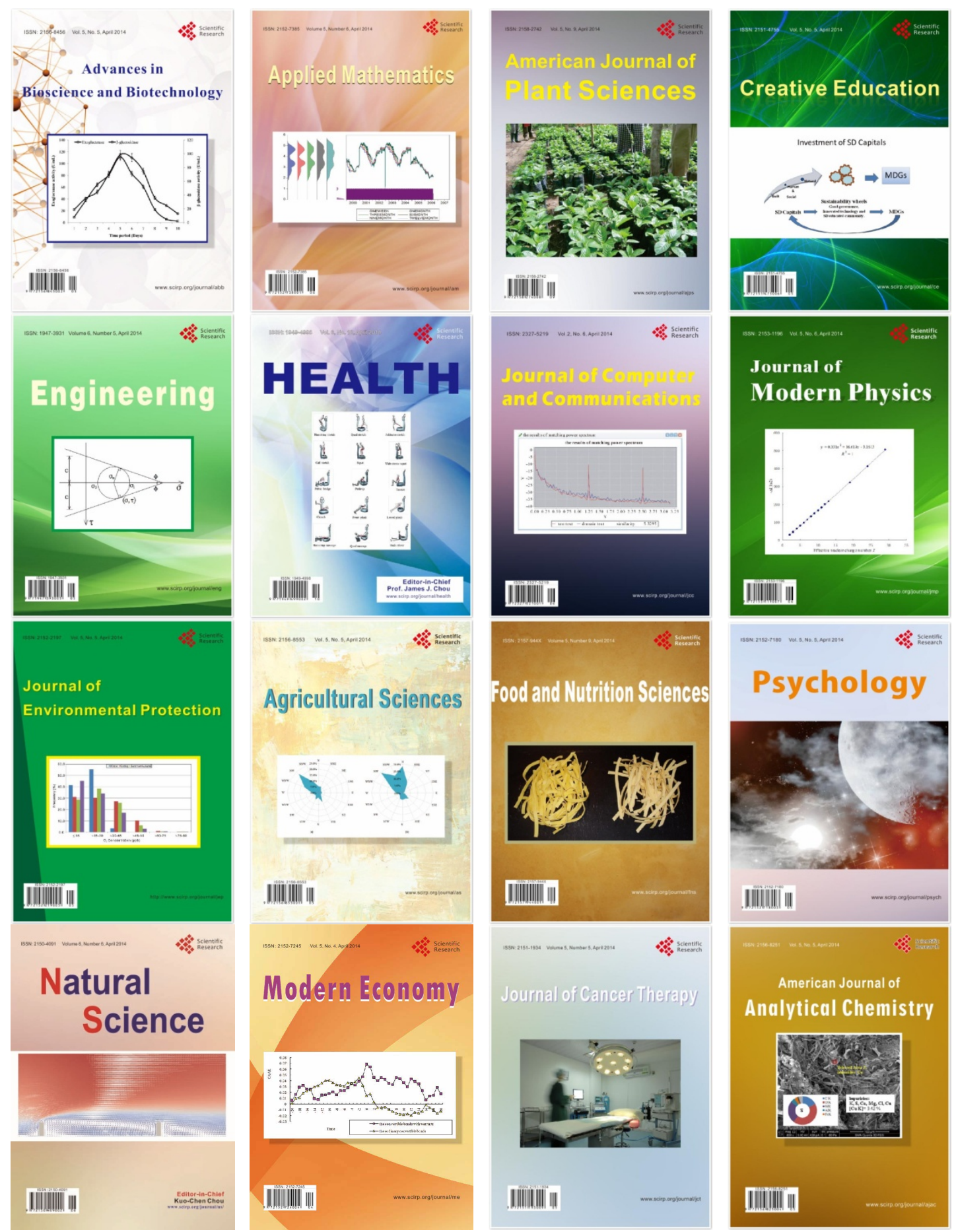